удК 330.101 .8

В. Ю. Буров

Забайкальский государственный университет,

2. Чита, Российская Федерация

В. В. Серватинский

Сибирский федеральньй университет,

2. Красноярск, Российская Федеращия

А. У. Ортыков

Забайкальская краевая лаборатория судебных экспертиз, 2. Чита, Российская Федерация

\title{
ОСОБЕННОСТИ ВЛИЯНИЯ ГОСУДАРСТВА НА ЭКОНОМИЧЕСКУЮ ДЕЯТЕЛЬНОСТЬ СУБЪЕКТОВ МАЛОГО ПРЕДПРИНИМАТЕЛЬСТВА В СОВРЕМЕННОЙ РОССИИ
}

АНнОТАЦИЯ. В статье рассматривается вопрос государственного регулирования экономической деятельности субъектов малого предпринимательства. Отмечается, что государственная политика по поддержке малого предпринимательства и определяет во многом особенности влияния государства на их экономическую деятельность. Проведен анализ государственной политики в области развития малого и среднего предпринимательства, который показал несоответствие части заявленных целей, принципов и мер нормативно-правового регулирования с реальным состоянием. Обоснован вывод о том, что оценку уровня влияния государства на экономическую деятельность сектора малого предпринимательства необходимо проводить на основе использования интегральных показателей по основным компонентам социально-экономического развития. Предложено, что организация системы государственного управления должна быть ориентирована на переосмысление роли государства в жизни общества - признания роли общественных организаций в процессе развития малого предпринимательства.

кЛючЕВЫЕ СлОВА. Малое предпринимательство; государственная политика; государственное влияние.

ИНФОРМАЦИЯ О СТАТЬЕ. Дата поступления 13 декабря 2016 г.; дата принятия к печати 11 января 2017 г.; дата онлайн-размещения 31 марта 2017 г.

\author{
V. Yu. Burov \\ Zabaikalye State University, \\ Chita, Russian Federation \\ V. V. Servatinsky \\ Siberian Federal University, \\ Krasnoyark, Russian Federation \\ A. U. Ortykov \\ Zabaikalye Territorial Laboratory of Forensic Enquiry, \\ Chita, Russian Federation
}

\section{FEATURES OF GOVERNMENTAL INFLUENCE \\ ON ECONOMIC ACTIVITIES OF SMALL BUSINESS ENTITIES IN MODERN RUSSIA}

\begin{abstract}
The article deals with the issue of governmental regulation of economic activities of small businesses entities. It is noted that the state policy in supporting small business does determine largely the features the state's influence on their economic activities. An analysis is made in regard of the state policy in the field of small and medium-sized business development, which showed a discrepancy of the stated goals, principles and measures of statutory regulation with the real situation.
\end{abstract}

(C) В. Ю. Буров, В. В. Серватинский, А. У. Ортыков, 2017

\section{Baikal Research Journal}


A conclusion is substantiated that estimating the level of the state's influence on the economic activities of the small business sphere sector must be carried out on the basis of using the integral indictors in terms of the major socio-economic development components. It is suggested that organizing the public administration system should be focused on rethinking the state participation in public life - recognition of public organizations in the process of developing small business.

KEYWORDS. Small business; state policy; government influence.

ARTICLE INFO. Received December 13, 2016; accepted January 11, 2017; available online March 31, 2017.

Отечественной наукой уделяется не достаточное внимание вопросам теории и практики государственной поддержки малого предпринимательства, а реальная ситуация в данном направлении говорит о ее не эффективности, что связано в том числе со слабой методологической базой и не системностью исследования данной проблемы. Это можно объяснить не только непрерывными изменениями во внешней среде, но и тем небольшим количеством научных публикаций посвященных данной проблеме.

Актуальность заявленной темы подкрепляется все возрастающими потребностями в структурной перестройкой экономики и в том числе переходе на инновационный путь развития, и как следствие, побуждает повышать эффективность государственного управления сектором малого предпринимательства (МП).

Среди отечественных ученых можно отметить ряд работ, посвященных вопросу методологии развития государственной поддержки малого предпринимательства. Так, А. О. Блинов предлагает создание «Центра стратегического развития территории и поддержки малого бизнеса» с внедрением алгоритма поэтапного проектирования и создания муниципального бизнес-инкубатора на основе функционально-структурного подхода» [1].

Е. М. Бухвальд и А. В. Виленский придерживаются позиции тенденции децентрализации государственной политике в отношении сектора МП, которая, по их мнению, приобретает значение одного из ключевых механизмов саморазвития территорий: «Необходимость децентрализации государственной политики развития и поддержки малого и среднего предпринимательства (МСП) как в России, так и в других странах основывается на очевидном факте привязки деятельности субъектов МСП к локальным ресурсам, к локальным рынкам, к ограниченной территории хозяйственной деятельности» [2].

В некоторых работах, особенности влияния государства на экономическую деятельность малого и среднего предпринимательства (МСП), рассматривается с точки зрения разработки Стратегии развития малого и среднего предпринимательства: «Стратегия должна обеспечить синхронизацию мер по поддержке МСП и, соответственно, создание условий для равного доступа к мерам поддержки. При этом повышение вклада малого бизнеса в валовой внутренний продукт страны до $40 \%$ должно быть общим стратегическим ориентиром. Для этого необходимо, чтобы МСП-сектор активно прирастал производственными, перерабатывающими предприятиями. Кроме того, для поддержки социального предпринимательства нужно выделить его в отдельную целевую группу [3].

Интересные подходы к данной проблеме существуют в зарубежной науке, что связано с масштабными изменениями в философии и парадигме государственного управления. В Концепции перестраивающегося правительства (Reinventing Government) еe авторы Д. Осборн и Т. Гэблер выдвинули следующие основные положения, среди которых можно отметить:

- обязательное наличие конкуренции между структурами, которые претендуют на предоставление услуг для правительства;

\section{Baikal Research Journal}

электронный научный журнал Байкальского государственного университета 
- предоставление местным сообществам больших полномочий;

- формирование и развитие модели «сервисного государства», предполагающей рассмотрение граждан как клиентов с целью повышения ответственности и деполитизации распределения средств между организациями госсектора, стимулирования инноваций и дифференциации услуг, уменьшение необоснованных расходов госсектора в текущей деятельности;

- приоритет конечному результату, обеспечивающий измерение результатов деятельности для устранения недостатков и совершенствования работы государственного аппарата [4, с. 53].

Вышеперечисленные положения во многом совпадают с позицией авторов данной работы, заключающей в следующем:

- выделение обособленной квоты для субъектов МП, при участии в государственных закупках;

- предоставление местным сообществам и общественным организациям право участия в управлении социально-экономического развития территории;

- внедрение объективных показателей оценивающих эффективность органов государственного управления в развитии сектора малого предпринимательства и др.

В административно-правовой науке под государственным управлением в широком смысле понимают регулирующую деятельность государства в целом, в узком - деятельность органов исполнительной власти на двух уровнях: федеральном и на уровне субъектов РФ. В целом государственное управление определяется в качестве практического, организующего и регулирующего воздействия государства на общественную и частную жизнедеятельность людей для ее упорядочения, сохранения или преобразования, которое опирается на его властную силу [5, с. 62].

Влияние государства на экономическую деятельность субъектов малого предпринимательства в своих работах рассматривает Г. Макарова, утверждающая, что на современном этапе развития усиливается зависимость результатов в экономике от таких макроэкономических признаков, как отсутствие у управляющей системы общей идеологии, способной объединить управляемые субъекты, что порождает «управленческую» неопределенность, обусловленную несовершенством государственного управления экономикой и обществом [6].

Интерес вызывает международный опыт: «...мировая практика свидетельствует о том, что в экономике стран с благоприятными условиями для предпринимательской деятельности (например, Германия, Дания, Канада, Новая Зеландия, Норвегия, Республика Корея, Швеция, Япония) государство традиционно принимает довольно заметное участие, в том числе устанавливая нормы и правила, которые способствуют развитию рыночных отношений, не создавая при этом неоправданных препятствий для развития частного сектора» [7].

Полностью соглашаясь с вышеизложенным, мы должны отметить тот факт, что данный вид неопределенности оказывает значительное влияние на многие процессы, в том числе и на развитие сектора малого предпринимательства. Иными словами, можно трактовать данное положение дел как известное правило «что не запрещено - то разрешено». Как отдельное направление развития малого предпринимательства можно рассматривать взаимодействие бизнес-структур и структур гражданского общества. Определения общих интересов развития, как среды проживания населения, так и получение дополнительных доход от удовлетворения потребностей именно конкретного населения. Более того отдельные организованные структуры гражданского общества, такие как органы территориального общественного самоуправления (ТОС), могут выступать самостоятельными хозяйствующими субъектами которые оказывают платные услуги для населения проживающих на территории данного ТОСа (охрана, вывоз мусора, досуговая и

\section{Baikal Research Journal}

электронный научный журнал Байкальского государственного университета 
культурно-массовая деятельность и пр.) Причем данное направление по логике развития качества жизни граждан должно получать активную поддержку у представителей местной (муниципальной) власти, поскольку, таким образом, происходит частичное решение вопросов местного значения.

Можно процитировать Президента РФ - В. В. Путина, который в своем Послании Федеральному Собранию от 1 декабря 2016 г. сказал дословно следующее; «Я хотел бы сейчас, уважаемые коллеги, обратиться ко многим из вас. Я хочу, чтобы меня услышали и губернаторы, и муниципальные власти. Я прошу вас, что называется, не жадничать, не отдавать по привычке, по накатанной предпочтения исключительно казенным структурам, а по максимуму привлекать к исполнению социальных услуг и некоммерческие организации. Все мы заинтересованы в том, чтобы активный приход НКО в социальную сферу вел к повышению качества ее. Поручаю Правительству совместно с законодателями завершить формирование четкой правовой базы деятельности НКО - исполнителей общественно полезных услуг, установить требования к их компетенции. Нужно ценить взыскательную, заинтересованную, деятельную позицию граждан. Еще раз хочу обратиться ко многим из вас: не прятаться в служебных кабинетах, не бояться диалога с людьми - идти навстречу, честно и открыто разговаривать с людьми, поддерживать их инициативы, особенно когда речь идет о таких вопросах, как благоустройство городов и поселков, сохранение исторического облика и создание современной среды для жизни» [8].

Особенности влияния государства на экономическую деятельность субъектов МП напрямую зависят от существующей государственной политики по поддержке сектора малого предпринимательства, включающая в себя в том числе федеральные и региональные программы по поддержки малых предприятий, которые являются механизмом влияния государства на экономическую деятельность субъектов малого предпринимательства в современной России. «Нужно продолжить идти в этом направлении системно и наступательно. Необходимы не абстрактные сценарии, в которых от нас мало что зависит, а профессиональный, выверенный прогноз развития. Надо четко определить, какой вклад в экономический рост внесут улучшение делового климата, запуск крупных инвестиционных проектов, наращивание не сырьевого экспорта, поддержка малого и среднего бизнеса, другие меры, какова будет роль регионов и отдельных отраслей производства» [8]. Такие задачи ставит сегодня Президент РФ.

Ранее проведенные одним из авторов (В. Ю. Буров) исследования показали, что государственная политика в России в области развития малого предпринимательства является малоэффективной и это подтверждается рядом выводов (табл.) [9].

Остановимся на одной из целей государственной политики в России в области развития малого предпринимательства: особенности участия субъектов МП в качестве поставщиков (исполнителей, подрядчиков) в целях размещения заказов на поставки товаров, выполнение работ, оказание услуг для государственных и муниципальных нужд. Анализ показывает, что стоимость контрактов 117737,8 млн р. за 2012 г. и 126757,1 млн р. за 2013 г. (2,7 и 3,1 \% соответственно от общей суммы контрактов).

И это говорит о неэффективности такой меры по поддержки субъектов МП. Подтверждение мы находим в Послание Президента Федеральному Собранию (2016 г.): «Также поручаю Правительству принять все необходимые решения, расширяющие доступ малых и средних предприятий к закупкам госкомпаний, в том числе четко определить обязательный годовой объем закупок госкомпаний у малого и среднего бизнеса. Это десятки и сотни миллиардов рублей, которые должны стать источником развития для отечественного предпринимательства» [8].

\section{Baikal Research Journal}

электронный научный журнал Байкальского государственного университета 


\section{Государственная политика в области развития} малого и среднего предпринимательства в Российской Федерации (в трактовке Федерального закона "О развитии малого и среднего предпринилательства в Российской Федерации" от 24 июля 2007 г. № 209-ФЗ)

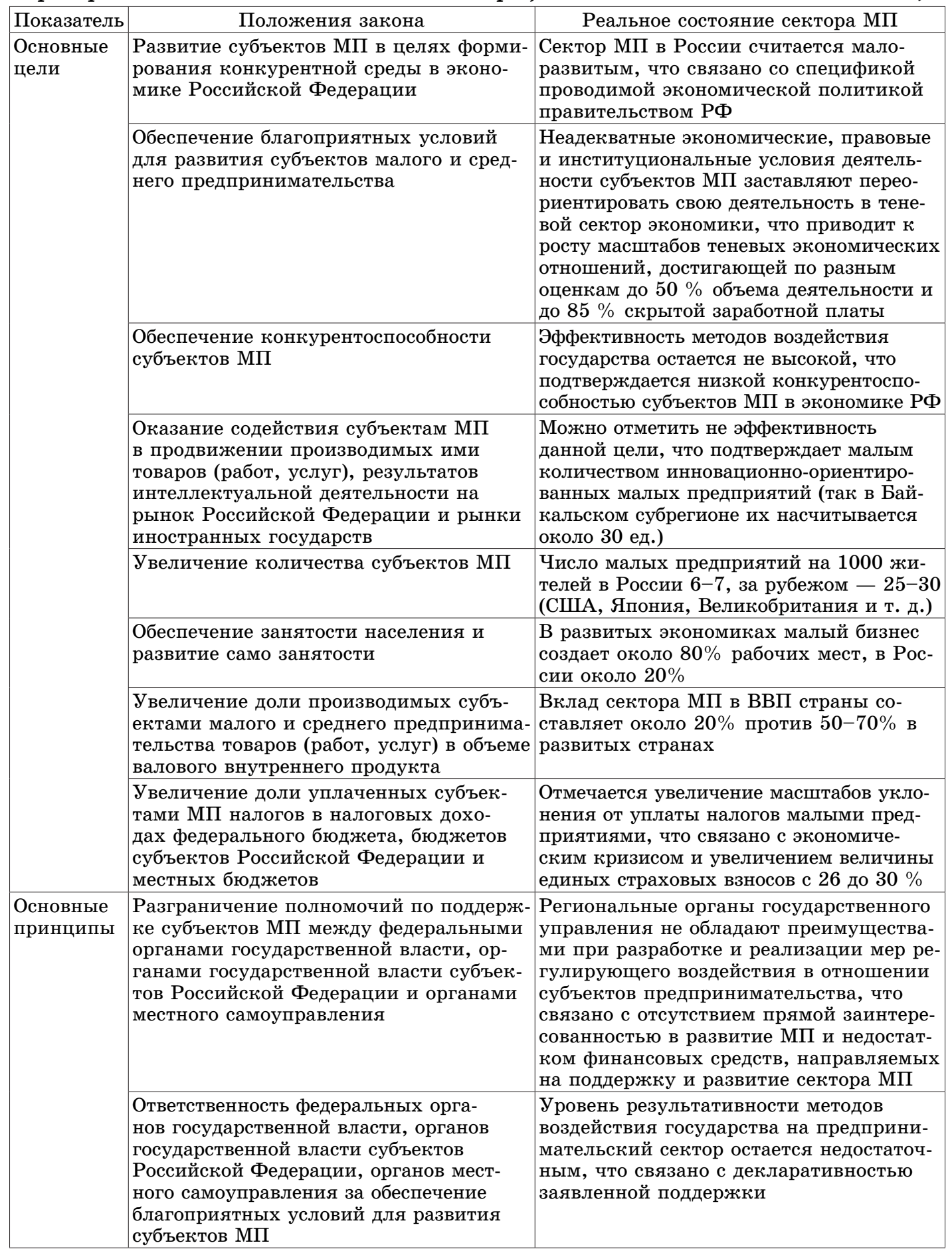

\section{Baikal Research Journal}


Окончание табл.

\begin{tabular}{|c|c|c|}
\hline Показатель & Положения закона & Реальное состояние сектора МП \\
\hline & $\begin{array}{l}\text { Участие представителей субъектов МП } \\
\text { в формировании и реализации гос. } \\
\text { политики в области развития МП, экс- } \\
\text { пертизе проектов нормативных право- } \\
\text { вых актов РФ, правовых актов органов } \\
\text { местного самоуправления, регулирую- } \\
\text { щих развитие МП }\end{array}$ & $\begin{array}{l}\text { Малоэффективный инструмент в связи с } \\
\text { инертностью и низким уровнем компе- } \\
\text { тентности основной массы самих пред- } \\
\text { принимателей (сектор МП) }\end{array}$ \\
\hline & $\begin{array}{l}\text { Обеспечение равного доступа субъектов } \\
\text { МП к получению поддержки в соответ- } \\
\text { ствии с условиями ее предоставления, } \\
\text { установленными федеральными, регио- } \\
\text { нальными и муниципальными програм- } \\
\text { мами развития МП }\end{array}$ & $\begin{array}{l}\text { Малоэффективный инструмент, особен- } \\
\text { но в части финансовой поддержки: } \\
\text { - слабая информированность; } \\
\text { - сложность нормативно-правовой базы; } \\
\text { - ничтожно малые объемы выделяемых } \\
\text { денежных средств }\end{array}$ \\
\hline \multirow[t]{8}{*}{$\begin{array}{l}\text { Меры } \\
\text { норматив- } \\
\text { но-пра- } \\
\text { вового } \\
\text { регулиро- } \\
\text { вания }\end{array}$} & $\begin{array}{l}\text { Специальные налоговые режимы, упро- } \\
\text { щенные правила ведения налогового } \\
\text { учета, упрощенные формы налоговых } \\
\text { деклараций по отдельным налогам и } \\
\text { сборам для малых предприятий }\end{array}$ & $\begin{array}{l}\text { Из пяти специальных налоговых } \\
\text { режимов наиболее востребованными } \\
\text { являются: упрощенная система налого- } \\
\text { обложения, патентная система нало- } \\
\text { гообложения (для ИПБОЮЛ) и уплата } \\
\text { единого налога на вмененный доход } \\
\text { по отдельным видам деятельности. } \\
\text { Причин слабого использования УСН и } \\
\text { ЕНВД две: законодательные ограниче- } \\
\text { ния на их применение и не урегулиро- } \\
\text { ванность проблем учета НДС }\end{array}$ \\
\hline & $\begin{array}{l}\text { Упрощенная система ведения бухгал- } \\
\text { терской отчетности для малых предпри- } \\
\text { ятий, осуществляющих отдельные виды } \\
\text { деятельности }\end{array}$ & $\begin{array}{l}\text { Введена для всех малых предприятий } \\
\text { не зависимо от видов деятельности }\end{array}$ \\
\hline & $\begin{array}{l}\text { Упрощенный порядок составления } \\
\text { субъектами малого и среднего пред- } \\
\text { принимательства статистической } \\
\text { отчетности }\end{array}$ & $\begin{array}{l}\text { Введен. Но хотят ввести ежекварталь- } \\
\text { ную отчетность по НДФЛ, и ежемесяч- } \\
\text { ную отчетность в ПФР (сейчас расчет } \\
\text { РСВ-1 заполняется и сдается ежеквар- } \\
\text { тально, а не ежемесячно) }\end{array}$ \\
\hline & $\begin{array}{l}\text { Льготный порядок расчетов за при- } \\
\text { ватизированное субъектами малого и } \\
\text { среднего предпринимательства госу- } \\
\text { дарственное и муниципальное иму- } \\
\text { щество }\end{array}$ & - \\
\hline & $\begin{array}{l}\text { Особенности участия субъектов МП в } \\
\text { качестве поставщиков (исполнителей, } \\
\text { подрядчиков) в целях размещения за- } \\
\text { казов на поставки товаров, выполнение } \\
\text { работ, оказание услуг для государствен- } \\
\text { ных и муниципальных нужд }\end{array}$ & $\begin{array}{l}\text { Стоимость контрактов } 117737,8 \text { млн р. } \\
\text { за } 2012 \text { г. и } 126757,1 \text { млн р. за } 2013 \text { г. } \\
\text { ( } 2,7 \text { и } 3,1 \text { \% соответственно от общей } \\
\text { суммы контрактов) }\end{array}$ \\
\hline & $\begin{array}{l}\text { Меры по обеспечению прав и законных } \\
\text { интересов субъектов МП при осущест- } \\
\text { влении государственного контроля } \\
\text { (надзора) }\end{array}$ & $\begin{array}{l}\text { Принятые меры по сокращению число } \\
\text { проверок при осуществлении государ- } \\
\text { ственного контроля (надзора) оказались } \\
\text { недостаточно эффективными }\end{array}$ \\
\hline & $\begin{array}{l}\text { Меры по обеспечению финансовой под- } \\
\text { держки субъектов МП }\end{array}$ & $\begin{array}{l}\text { Недоступность и дороговизна заемных } \\
\text { финансовых средств. Недостаточный } \\
\text { объем финансирования развития сек- } \\
\text { тора МП из региональных бюджетов - } \\
\text { около 1-2 \% }\end{array}$ \\
\hline & $\begin{array}{l}\text { Меры по развитию инфраструктуры } \\
\text { поддержки субъектов МП }\end{array}$ & - \\
\hline
\end{tabular}

\section{Baikal Research Journal}


Изменения уровня влияния государства на экономическую деятельность сектора МП можно оценить внедрением объективных критериев, оценивающих эффективность государственного регулирования малого предпринимательства.

Существующие критерии оценивания уровня развития сектора МП, определяют в основном количественные изменения сектора МП, что не отражает качественные изменения. Так Д. И. Дроздова, предлагает сосредоточиться на трех основных задачах:

- увеличение доли малых предприятий в субъектах РФ;

- повышение доли занятых в сфере малого бизнеса в регионе;

- увеличение совокупного оборота малого бизнеса среди остальных компаний в регионе [10].

Нами полностью поддерживается позиция группы ученых, которые считают, что система оценочных показателей должна одновременно решать несколько задач:

- отражать динамику развития малого предпринимательства в регионе в официальном секторе экономики;

- проводить оценку эффективности деятельности органов власти на любом этапе реализации программ поддержки предпринимательства;

- сравнивать эффективность работы органов власти различных территорий (соответствовать принципу сопоставимости);

- проводить на постоянной основе мониторинг реализации программы в секторе МП, а также корректировать программу по результатам мониторинга $[11$, c. $86-87]$.

Оценку уровня влияния государства на экономическую деятельность сектора МП необходимо проводить на основе: «Использования интегральных показателей уровня состояния сектора МП в регионе по основным компонентам социально-экономического развития и подхода, позволяющего оценить степень обеспечения необходимыми экономическими и правовыми условиями субъектов МП при осуществлении ими экономической деятельности в официальном секторе экономики» [12].

Нужно отметить, что несомненная перспективность сектора малого предпринимательства в современной экономике во многом определяется влиянием государства на их экономическую деятельность. И, следовательно, качественное изменение состояние сектора МП следует рассматривать через призму структурных изменений в экономике, что зависит от государственной политики по поддержке малого предпринимательства.

Именно малые предприятия, в случае разработки новой государственной политики в области малого предпринимательства с инновационным уклоном, могут стать основой рыночных структур во многих отраслях, обеспечить перелив инвестиций в сферы наиболее эффективного приложения ресурсов и тем самым соединить процессы структурной политики и формирование всероссийского рынка.

При этом, как нам кажется, организация системы государственного управления должна быть ориентирована на переосмысление роли государства в жизни общества - признания общественных организаций в процессе развития малого предпринимательства, что влечет функциональную трансформацию структуры исполнительных органов в аспекте совершенствования механизмов взаимодействия государства, общества и бизнеса.

\section{Список использованной литературы}

1. Блинов А. О. Стратегическое развитие территории и поддержки малого бизнеса. Корпоративное управление и инновационное развитие экономики Севера / А. О. Блинов // Корпоративное управление и инновационное развитие экономики Севера. - 2011. № 4. - C. 1-3.

\section{Baikal Research Journal}


2. Бухвальд Е. М. Децентрализация в государственной политике развития и поддержки малого и среднего предпринимательства в России / Е. М. Бухвальд, А. В. Виленский // Вестник Института экономики Российской академии наук. - 2015. - № 1. - С. 81-96.

3. Грибанова Н. С. Основные положения поддержки в развитии малого и среднего бизнеса России / Н. С. Грибанова, Н. Н. Грибанова // Baikal Research Journal. — 2015. T. 6, № 5. - DOI : 10.17150/2411-6262.2015.6(5).1.

4. Osborne D. Reinventing Government How the Enterpreneurial Spirit is Transforming The Public Sector / D. Osborne, T. Gaebler. - New York : Addison-Wesley, 1992. — 436 p.

5. Атаманчук Г. В. Теория государственного управления / Г. В. Атаманчук. - М. : Омега-Л, 2004. - 528 с.

6. Макарова Г. Н. «Управленческая» неопределенность в российской экономике / Г. Н. Макарова. - Иркутск : Изд-во БГУЭП, 2010. - 191 с.

7. Санина Л. В. Опыт оказания государственной поддержки субъектам малого и среднего предпринимательства в регионах России [Электронный ресурс] // Известия Иркутской государственной экономической академии (Байкальский государственный университет экономики и права). - 2014. - № 3. - Режим доступа: http://eizvestia.isea.ru/ reader/article.aspx?id=19113.

8. Путин В. В. Послание президента Федеральному Собранию. 2016 [Электронный ресурс] / В. В. Путин. - Режим доступа: http://kremlin.ru/events/president/news/53379.

9. Буров В. Ю. Теория и методология развития государственной системы противодействия теневой экономической деятельности субъектов малого предпринимательства : дис. ... д-ра экон. наук : 08.00.05 / В. Ю. Буров. - СПб., 2015. - 274 с.

10. Дроздова Д. И. Оценка эффективности системы государственной поддержки малого бизнеса / Д. И. Дроздова, В. В. Залешина // Professional Science. - 2016. — № 4. - С. 25-29.

11. Государственное регулирование развития предпринимательства: опыт, проблемы, инновации / под ред. А. Я. Быстрякова. - М. : Проспект, 2015. - 144 с.

12. Буров В. Ю. Формирование и проведение мониторинга состояния малого предпринимательства на региональном уровне / В. Ю. Буров // Известия Байкальского государственного университета. - 2016. - T. 26, № 5. - C. 731-738. — DOI: 10.17150/25002759.2016.26(5).731-738.

\section{References}

1. Blinov A. O. Strategic development of the territory and small business support. Korporativnoe upravlenie $i$ innovatsionnoe razvitie ekonomiki Severa $=$ Corporative management and innovative economic development of the Northern Territories, 2011, no. 4, pp. 1-3. (In Russian).

2. Buchwald E. M., Vilensky V. A. Decentralization in the state policy of small and medium-sized business development and support in Russia. Vestnik Instituta ekonomiki Rossiiskoi akademii nauk = Bulletin of Institute of Economics of Russian Academy of Sciences, 2015, no. 1, pp. 81-96. (In Russian).

3. Gribanova N. S., Gribanova N. N. Basic provisions for supporting development of small and medium-sized businesses in Russia. Baikal Research Journal, 2015, vol. 6, no. 5. DOI: 10.17150/2411-6262.2015.6(5).1. (In Russian).

4. Osborne D., Gaebler T. Reinventing Government: How the Entrepreneurial Spirit is Transforming the Public Sector. New York, Addison-Wesley, 1992. $436 \mathrm{p}$.

5. Atamanchuk G. V. Teoriya gosudarstvennogo upravleniya [Public Administration Theory]. Moscow, Omega-L Publ., 2004. 528 p.

6. Makarova G. N. «Upravlencheskaya» neopredelennost v rossiiskoi ekonomike [ Managerial» Uncertainty in Russian Economy]. Irkutsk, Baikal State University of Economic and Law Publ., 2010. 191 p.

7. Sanina L. V. Experience of giving state support to small and medium- business entities in Russia's regions. Izvestiya Irkutskoi gosudarstvennoi ekonomicheskoi akademii (Baykalskii gosudarstvennyi universitet ekonomiki i prava) = Bulletin of Irkutsk State Economics Academy (Baikal State University of Economics and Law), 2014, no. 3. Available at: http://eizvestia. isea.ru/reader/article.aspx?id=19113. (In Russian).

8. Putin V. V. Poslanie prezidenta Federal'nomu Sobraniyu. 2016 [President's message to the Federal Assembly. 2016]. Available at: http://kremlin.ru/events/president/news/53379. (In Russian).

\section{Baikal Research Journal}

электронный научный журнал Байкальского государственного университета 
9. Burov V. Yu. Teoriya I metodologiya sovershenstvovaniya gosudarstvennoi sistemy protivodeistviya tenevoi ekonomicheskoi deyatel'nosti sub»ektov malogo predprinimatel'stva. Dokt. Diss. [Theory and Methodology of Improving State Policy in Combating Shadow Economic Activities of Small Businesses. Doct. Diss.]. Saint-Petersburg, 2015. 276 p.

10. Drozdov D. I., Salesin V. V. Evaluating effectiveness of state support of small business system. Professional Science, 2016, no. 4, pp. 25-29. (In Russian).

11. Bystryakov A. Ya. (ed.). Gosudarstvennoe regulirovanie razvitiya predprinimatel'stva: opyt, problemy, innovatsii [State regulation of business development: experience, problems, innovations]. Moscow, Prospekt Publ., 2015. 144 p.

12. Burov V. Yu. Monitoring of small business at the regional level. Izvestiya Baykalskogo gosudarstvennogo universiteta = Bulletin of Baikal State University, 2016, vol. 26, no. 5, pp. 731-738. DOI: 10.17150/2500-2759.2016.26(5).731-738. (In Russian).

\section{Информация об авторах}

Буров Виталий Юрьевич - доктор экономических наук, доцент, зав. кафедрой экономической теории и мировой экономики, Забайкальский государственный университет, 672039, г. Чита, ул. Александро-Заводская, 30, e-mail: burovschool@rambler.ru.

Серватинский Вячеслав Вячеславович - кандидат экономических наук, доцент, доцент кафедры проектирования зданий и экспертизы недвижимости Инженерно-строительного института, Сибирский федеральный университет, 660041, Красноярск, пр. Свободный, 82, e-mail: vvs024@yande.ru.

Ортыков Алриддин Укталович - директор, Забайкальская краевая лаборатория судебных экспертиз, 672039, г. Чита, ул. Александро-Заводская, 30, e-mail: ortykov_amir@list.ru.

\section{Authors}

Vitaly Yu. Burov - Doctor habil. (Economics), Associate Professor, Head of Chair of Economic Theory and World Economy, Zabaikalye State University, 30 Aleksandro-Zavodskya St., 672039, Chita, Russian Federation; e-mail: burovschool@rambler.ru.

Vyacheslav V. Servatinsky - PhD in Economics, Associate Professor, Chair of Building Design and Real Estate Expertise, Engineering and Construction Institute, Siberian Federal University, 82 Svobodny St., 660041, Krasnoyarsk, Russian Federation; e-mail: vvs024@yande.ru.

Amriddin U. Ortikov - General Director, Zabaikalye Territorial Laboratory of Forensic Enquiry, 30 Aleksandro-Zavodskya St S, 672039, Chita, Russian Federation; e-mail: ortykov_ amir@list.ru.

\section{Библиографическое описание статьи}

Буров В. Ю. Особенности влияния государства на экономическую деятельность субъектов малого предпринимательства в современной России / В. Ю. Буров, В. В. Серватинский, А. У. Ортыков // Baikal Research Journal. - 2017. — T. 8, № 1. - DOI: 10.17150/24116262.2017.8(1).5.

\section{Reference to article}

Burov V. Yu., Servatinsky V. V., Ortykov A. U. Features of governmental influence on economic activities of small business entities in modern Russia. Baikal Research Journal, 2017, vol. 8, no. 1. DOI: 10.17150/2411-6262.2017.8(1).5. (In Russian).

\section{Baikal Research Journal}

